Su, H. et al. (2013). Optimization of gas diffusion electrode for polybenzimidazole-based high temperature proton exchange membrane fuel cell: Evaluation of polymer binder in catalyst layer. International Journal of Hydrogen Energy, 38: 11370 - 11378. http://dx.doi.org/10.1016/j.ijhydene.2013.06.107

\title{
Optimization of gas diffusion electrode for polybenzimidazole-based high temperature proton exchange membrane fuel cell: Evaluation of polymer binders in catalyst layer
}

Huaneng Su, Sivakumar Pasupathi, Bernard Bladergroen, Vladimir Linkov and Bruno G. Pollet

\begin{abstract}
Gas diffusion electrodes (GDEs) prepared with various polymer binders in their catalyst layers (CLs) were investigated to optimize the performance of phosphoric acid doped polybenzimidazole (PBI)-based high temperature proton exchange membrane fuel cells (HT-PEMFCs). The properties of these binders in the CLs were evaluated by structure characterization, electrochemical analysis, single cell polarization and durability test. The results showed that polytetrafluoroethylene (PTFE) and polyvinylidene difluoride (PVDF) are more attractive as CL binders than conventional PBI or Nafion binder. At ambient pressure and $160 \mathrm{O}$, the maximum power density can reach $\mathrm{w} 0.61 \mathrm{~W} \mathrm{~cm}^{-2}$ (PTFE GDE), and the current density at $0.6 \mathrm{~V}$ is up to ca. $0.52 \mathrm{~A} \mathrm{~cm}^{-2}$ (PVDF GDE), with $\mathrm{H}_{2}$ /air and a platinum loading of $0.5 \mathrm{mg} \mathrm{cm}^{-2}$ on these electrodes. Also, both GDEs showed good stability for fuel cell operation in a short term durability test.
\end{abstract}

\section{Introduction}

Polybenzimidazole (PBI) based high temperature proton exchange membrane fuel cells (HT-PEMFCs) have attracted more and more attention in recent years due to their advantages over low temperature PEMFCs based on perfluorosulphonic acid polymer electrolytes (e.g. Nafion) [1]. With the capability of operating at 120 200 $\mathrm{O}$ C, HT-PEMFCs are very promising alternative power generation devices due to their (1) faster electrode kinetics, (2) low dependency on cooling system, (3) high amount of reusable heat energy, (4) high tolerance to pollutants (e.g. CO), and (5) high practicability in mixed hydrogen systems [2e4]. They are commonly used in stationary fuel cell systems to increase tolerance to reforming gas and minimize the purification requirements for a reforming system. Also, high temperature operation can eliminate the need for a humidification unit, which can be very beneficial for fuel cell vehicle applications [5]. However, the sluggish kinetics of the oxygen reduction reaction (ORR) and 
the transport limitations of protons and reactants in the cathode, especially in the presence of phosphoric acid (PA), limit the cell performance of HTPEMFCs [6]. Therefore, improving the performance of HT-PEMFCs is one of the most important issues to be dealt with before such system can be considered more widely as an alternative to low temperature PEMFC systems.

At present, almost all the electrodes for HT-PEMFCs are fabricated by depositing a catalyst layer (CL) in the form of catalyst ink on top of a gas diffusion layer (GDL) [7e10]. Typically, the CL contains two substances: an electrocatalyst (i.e. Pt/C etc.) and a polymeric binder. In addition to maintaining the integrity of the $\mathrm{CL}$, the binder plays an important role in determining the electrode performance. It concerns, on the one hand, the mechanical properties of the CL and on the other hand the gas permeability, PA impregnation, platinum utilization and ORR in the electrodes of the HTPEMFC.

For PBI-based HT-PEMFCs, the polymer binders used include sulphonated polymer, e.g. Nafion, which in combination with PA has proton conductivity at high temperature [11], PBI [9,12,13], polytetrafluoroethylene (PTFE) [8] or PBIepolyvinylidene difluoride (PVDF) [14e17] blend with subsequent PA doping, or other polymers [18] that contain functional groups for incorporating PA. For example, Modestov et al. [19] investigated the utilization of Nafion and fluorinated ethylenepropylene (FEP) as a CL binder. Their results showed that Nafion had a detrimental effect on the performance of this type of fuel cell. The difference in binder influence on MEA performance was ascribed to the difference in the structures of the networks formed by particles of these binders within the CL. They suggested that a minimum quantity of binder, sufficient to maintain the integrity of the CL, was optimal. Mazu'r et al. [20] investigated gas diffusion electrodes (GDEs) utilizing both PBI as well as PTFE binder in their CLs. They found significantly higher danger of the CL flooding by PA when using hydrophilic PBI as a binder. In the case of PTFE, the danger of such behavior was relatively low with a sufficiently thick CL $(>30 \mathrm{~mm})$. For the thinner CL, a sufficiently high PTFE content should be used. In the work of Park et al. [18], three different binders, PBI, PTFE and polyurethane were studied. Their results showed that $\mathrm{Pt}$ utilization depends on the kind of binders used in the electrodes. The PBI binder was found to reduce Pt utilization, and only $10 \%$ catalyst utilization was measured. Increasing PTFE content in the electrode was considered as a possible way to operate cells for a longer period.

Although some useful conclusions can be drawn from the abovementioned works, the binders investigated in these works were limited,

\section{http://repository.uwc.ac.za}


and some binders (e.g. polyurethane) are not typically used in practical systems. Some common binders, such as PVDF, have not been fully studied yet. In this work, five different binders (Nafion, PBI, PTFE, PVDF and PBIePVDF blend) were investigated to evaluate their effect on the GDE performance of PBI-based HT-PEMFCs. The properties of these binders in the CL were fully evaluated by structure characterization, electrochemical analysis, single cell polarization, activation and durability tests.

\section{Experimental}

\subsection{Preparation of catalyst inks}

The catalyst used for both anode and cathode layers was Hispec Pt/C (40 wt\% Pt, Johnson Matthey). Catalyst binders included in the ink formulation were either 5 wt\% Nafion solution (SigmaeAldrich), or 60 wt\% PTFE emulsion (Electrochem Inc.), or lab-made 5 wt\% PBI/DMAc solution, or labmade 5 wt\% PVDF/DMAc solution. The catalyst inks were prepared by dispersing catalyst powder into a mixture of solvent and catalyst binder. The mixture was dispersed ultrasonically for $40 \mathrm{~min}$ before being used.

\subsection{Fabrication of GDEs}

All GDEs used in this study were prepared by an automatic catalyst spraying under irradiation method [21]. The catalyst powders were deposited onto the microporous layer of commercially available GDL (H2315-CX196, Freudenberg, Germany). The catalyst loadings were calculated by weighing the GDEs before applying the catalyst ink, and then after application and overnight oven drying. The platinum loadings of all GDEs (both anode and cathode) used for this study are $0.5 \mathrm{mg} \mathrm{cm}^{-2}$, unless otherwise stated. The active area of the prepared GDEs was $5 \mathrm{~cm}^{2}$. By using different polymer binders, five types of GDEs were prepared, which are detailed in Table

1. It should be noted that the binder content in the CLs of these GDEs are different from each other, which were obtained from some researchers' works $[15,22]$ or optimized by the authors.

\subsection{Physical characterization of the GDEs}

Pore size distribution was determined by using an Auto Pore IV $9500 \mathrm{Hg}$ porometer (Micromeritics Instrument Corp., USA). A Zeiss SEM (Oberkochen, Germany) was employed to observe the surface morphologies and porous microstructure of the GDEs.

\section{http://repository.uwc.ac.za}




\begin{tabular}{lllll}
\hline Table 1 - Specifications of GDEs. & & & \\
\hline GDE type & Binder & $\begin{array}{c}\text { Binder } \\
\text { content in CL }\end{array}$ & Solvent & Post-treatment \\
\hline Nafion GDE & Nafion & $\sim 23 w t \%$ & $\mathbb{P P A} / \mathrm{H}_{2} \mathrm{O}$ & Oven drying $110^{\circ} \mathrm{C}$ \\
PTFE GDE & PTFE & $\sim 30 \mathrm{wt} \%$ & $\mathrm{IPA} / \mathrm{H}_{2} \mathrm{O}$ & Sintered at $350^{\circ} \mathrm{C}$ \\
PBI GDE & PBI & $\sim 16.7 \mathrm{wt} \%$ & $\mathrm{DMAc}$ & Oven drying $170^{\circ} \mathrm{C}$ \\
PVDF GDE & PVDF & $\sim 15 \mathrm{wt} \%$ & Oven drying $170^{\circ} \mathrm{C}$ \\
PBI-PVDF GDE & PBI-PVDF & $\sim 10 \mathrm{wt} \%$ & DMAc & Oven drying $170^{\circ} \mathrm{C}$ \\
& blend & & & \\
\hline
\end{tabular}

\subsection{MEA and single cell test}

The membranes used in this study are AB-PBI (poly(2,5-benzimidazole)), which were supplied by FuMA-Tech (fumapem ${ }^{\circledR}$ AM, w35 mm). Doping with PA was achieved by immersing the membranes in 85\% acid solution for $24 \mathrm{~h}$ at $85 \mathrm{O} \mathrm{C}$, which gave the membrane an acid doping level of about 3.8 molecules of $\mathrm{H}_{3} \mathrm{PO}_{4}$ per polymer repeating unit (PRU). Before being used, the membrane was removed from the PA bath, and the superficial acid on the membrane was thoroughly wiped off with a lab tissue. The thickness of the acid doped membrane is about $80( \pm 5) \mathrm{mm}$.

Together with gaskets made of fluorinated polymer, the MEA was assembled by sandwiching the doped membrane between two GDEs impregnated with PA in a single cell fixture (BalticFuelCells $\mathrm{GmbH}$, Germany), without preceding hotpressing step. The cell fixture consists of two graphite plates with serpentine channels. Electrical heaters and a thermo-couple were embedded into the plates and connected to a cell compression unit (Pragma Industries, France), which controlled the cell temperature at $160 \mathrm{O} \mathrm{C}$ and the piston pressure at 2 $\mathrm{N} / \mathrm{mm}^{2}$ in this study.

The cells were operated in a FuelCon Evaluator C test station (FuelCon, Germany). Pure hydrogen was fed to the anode and air to the cathode respectively, with flow rates of $200 \mathrm{ml} \mathrm{min}^{-1}$ (hydrogen) and $1000 \mathrm{ml}$ $\min ^{-1}$ (air), at ambient pressure. Both hydrogen and air were used as dry gases, directly from the compressed cylinders without external humidification. Prior to the recording of the polarization curves, the MEAs were activated by operating the unit cell at a constant voltage $(0.60 \mathrm{~V})$ under the cell temperature of $160^{\circ} \mathrm{C}$ until a stable performance was obtained. The currentevoltage polarization curves were obtained by measuring the current density with the stepwise decrement of voltage from 0.9 to $0.2 \mathrm{~V}$, with an interval of $0.05 \mathrm{~V}$. At each cell voltage, the current was measured after a hold time of 5 min to allow the cell approaching steady state. 


\subsection{Electrochemical measurements}

Electrochemical impedance spectroscopy (EIS) and cyclic voltammetry (CV) were performed using an Autolab PGSTAT 30 Potentiostat/Galvanostat (Metrohm) equipped with a $10 \mathrm{~A}$ booster and a frequency response analysis (FRA) module. The impedance data were generated and simulated using the Autolab Nova software. During EIS tests, the anode was served as both the reference electrode (RE) and the counter electrode (CE) since the polarization of hydrogen reduction reaction (HRR) is negligible compared to that for OER at cathode during fuel cell operation. The impedance spectra were recorded at a cell potential of $0.6 \mathrm{~V}$ in the frequency range of $0.1 \mathrm{e} 10,000$ $\mathrm{Hz}$ with sinusoidal amplitude of $5 \mathrm{mV}$.

Voltammetric measurements, undertaken to study the electrochemical active surface area (EASA), were conducted using dry $\mathrm{N}_{2}$ at the cathode (working electrode, WE) and dry $\mathrm{H}_{2}$ at the anode (CE and $\mathrm{RE}$ ). Cyclic voltammograms were recorded from $1.2 \mathrm{~V}$ to $0.05 \mathrm{~V}$ at a scan rate of $0.05 \mathrm{~V} \mathrm{~s}^{-1}$.

\section{Results and discussion}

\subsection{Structural analysis}

Fig. 1 shows the SEM images of the GDEs prepared with various polymer binders. It can be seen that the surface morphology of the PTFE GDE is obviously different than those of the other four GDEs. When PTFE is used as binder, it exists as colloidal solid particles in the catalyst ink, which easily forms large size agglomerates, as shown in Fig. 1(a). While PVDF, PBI or Nafion were used as binders, the polymers remain soluble in the inks, and therefore, the formation of big agglomerates is less likely and the surface of these GDEs are more uniform, as shown in Fig. 1(c,e,g,i). Fig. 1(b,d,f,h,j) shows the pore structures of the CLs for the five GDEs, it can be discerned that the GDEs prepared with "soluble binders" show a more uniform and denser structure (Fig. 1(d,f,h,j)) when compared to the PTFE GDE (Fig. 1(b)). Although the large catalyst agglomerates make the CL surface uneven (Fig. 1(a)), it does not seem to be a problem for interface contact with PBI membrane due to the pliability of PA-doped membrane and the considerably low assembly pressure of the MEA. However, the denser CL structures might impair the mass transfer through them, leading to a poor utilization, which illustrates the importance of maximizing the total pore volume in the CL $[20,23,24]$.

In order to better understand the differences among the CL structures of these electrodes, the pore sizes characterizations of the GDEs by mercury intrusion method were performed (Fig. 2). The proper distribution of pores is an important parameter of a GDE, since the reactant gases and water 
(liquid or vapor) transport are regulated by the specific volumes of small and large pores [25]. Normally, the pores in the CL can be divided into three classes according to their sizes, namely: micropores (pore diameter from 0.03 to $0.1 \mathrm{~mm}$ ), mesopores (the intermediate range between 0.1 and $5 \mathrm{~mm}$ ) and macropores (pore diameter from 5 to $100 \mathrm{~mm}$ ) [26]. The pores larger than about $100 \mathrm{~mm}$ stem from fissures on the surface of the diffusion layer [26]. From Fig. 2, it can be seen that all these curves are similar except in the macropore zone (i.e. 5e100 $\mathrm{mm}$ ), where the specific pore volume of these electrodes are in order of PTFE $>$ PVDF $>$ PBI/PVDF blend $>$ PBI $z$ Nafion. This result is reasonable, considering the larger catalyst agglomerates in the PTFE GDEs and the fact that PTFE and PVDF melt and transform into a fiber phase at high sintering temperature. Also, it can be seen that the micropore volume of the PTFE electrode increased during heat treatment, in the range of 0.07 eo.1 mm (see Fig. 2(a)), which should result from the melting and re-dispersion of PTFE in the interior of the CL. In the case of gas transport to the catalyst sites [25], the main contribution to gas transport will be due to Knudsen diffusion in the micropores and a molecular diffusion mechanism in the macropores. Better mass transport would be expected for the electrodes with larger volume of the pores, especially at high current densities. 

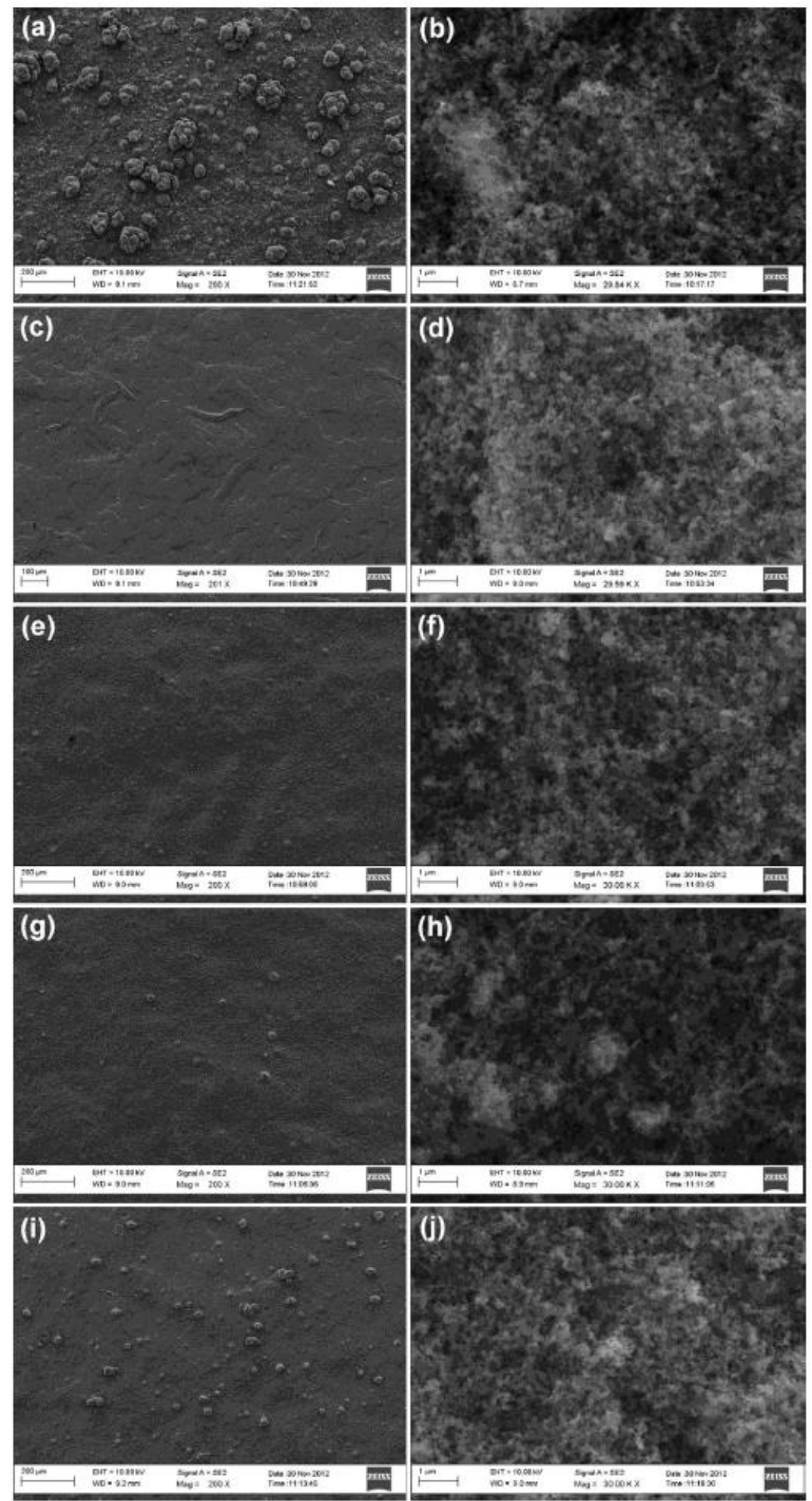

Fig. 1 - SEM images showing the surface morphologies and the porous structures of the GDEs with various polymer binders. (a) and (b) PTFE; (c) and (d) PVDF; (e) and (f) PBI-PVDF blend; (g) and (h) PBI; (i) and (j) Nafion.

\subsection{Single cell performance}

Fig. 3 shows the single cell performance of the five different GDEs. It is clear that the PTFE and PVDF GDEs yield much better performance than the GDEs prepared with PBI, Nafion or PBI/PVDF blend binders in all regions

\section{http://repository.uwc.ac.za}


of the polarization curve. At a working voltage of $0.6 \mathrm{~V}$, the current density of the MEA with PVDF GDEs reaches $0.53 \mathrm{~A} \mathrm{~cm}^{-2}, 121 \%$ higher than that $(0.24 \mathrm{~A}$ $\mathrm{cm}^{-2}$ ) of the MEA with PBI GDEs. The maximum power density of the MEA with PTFE GDEs can reach $0.61 \mathrm{~W} \mathrm{~cm}^{-2}$ at $0.35 \mathrm{~V}$. These values are among the best results yet reported for similar PA-doped PBI fuel cell operated using air, and comparable to the performances of the commercial MEAs with high Pt loadings [27].

To explain the performance of these GDEs prepared with different polymer binders, an overall analysis on the polarization curves are performed. According to the rate of voltage drop, a fuel cell polarization curve is generally divided into three segments corresponding to different electrochemical processes. At a very low current density, the first drop of the curve is attributed to the sluggish kinetics of the reactions (prevalent in oxygen reduction reaction) on the catalyst sites, determined by the nature of the electrodes. It can be seen in

Fig. 2 e (a) Specific and (b) cumulative pore volume distribution of the electrodes with different polymer binders. Fig. 3(a) that the single cell with PVDF GDEs shows minor voltage drop than do other GDEs at this region (oeo.1 $\mathrm{A} \mathrm{cm}^{-2}$ ), which means the structure of the PVDF GDE is more effective to enhance the kinetics of ORR than the other GDEs. This is mainly attributable to the properties of PVDF binder that exists in the CLs as a fiber phase, which makes catalyst particles less likely to be encapsulated in the binder, and thereby making more Pt surface available in the CLs. On the contrary, PBI and Nafion polymer ionomers easily covered on the surface of the catalyst particles, which could impose mass transport limitation in CLs due to the low gas permeability in these films formed on the catalyst sites. Although PTFE has similar properties as PVDF binder, the distribution of PTFE in CL might be less uniform than that of PVDF because of the insolubility of PTFE polymer in the catalyst ink [28]. This might be the reason that PTFE GDE shows a second best performance in this region.

The subsequent drop in the polarization curve is due to ohmic loss, which comprises ionic resistances of the membrane and the CLs, electronic resistances of each cell component (i.e. CLs, backing layers and bipolar plates) and the interfacial contact resistances between them. As shown in Fig. 3(a), the PTFE, PVDF and PBI/PVDF GDEs present similar decreasing slopes in the linear region, implying that they have similar ohmic cell resistances. It is reasonable because these GDEs are fabricated with the same membrane, same catalyst loading, and also tested in the same fixture. Although PTFE GDE has a higher PTFE content (w3o wt\%) in the CL, the electric resistance did not seem affected by the PTFE binder since the 
catalyst particles are less likely to be encapsulated by the binder, which has also been observed in other researchers' works $[8,29]$. However, the PBI GDE and Nafion GDE show sharp voltage drops in this linear region, meaning they have higher ohmic resistances than those of other three GDEs. This might arise from the cover effect of the PBI and Nafion binders, resulting in more catalyst agglomerates isolated in the CLs.

The last voltage drop of the polarization curve at high current density is ascribed to mass transport limitations. However, from Fig. 3(a) it can be seen that, for the GDEs prepared with PTFE, the voltage drop rate in the high current density region $\left(>1.5 \mathrm{~A} \mathrm{~cm}^{-2}\right.$ ) of the polarization curve is almost same with that in the linear region, which means that no obvious mass transfer limitation in PTFE GDEs even at high current densities. It is understandable when considering the high operating temperature $(160 \mathrm{O}$, only water vapor existed in the GDEs), the porous structures, as well as the highly hydrophobic CLs resulting from the use of PTFE. Therefore, the transport of water in the whole GDEs could be balanced easily. Transport of reactants $\left(\mathrm{H}_{2}\right.$ and air) in the CLs can be enhanced since there is no flooding problem expected in the electrodes [30]. Furthermore, the elimination of liquid water can also increase the exposed surface area of the electrocatalysts and improve the ability of the reactants to diffuse into the reaction layers [31]. These could be the reasons why PTFE GDE reached its maximum power density at low cell voltage $(0.35 \mathrm{~V})$, which also can be observed in many researchers' works [8,27,29,32]. For PVDF GDE and PBI/PVDF GDE, the hydrophobicities and the porosities of their CLs are not as high as that of PTFE GDEs, which could be the reason why the two GDEs have more voltage drops in this region. On the contrary, the GDEs prepared with hydrophilic binders (Nafion and PBI) show much worse performance in this region because of the cover effect and the low gas permeability in these films formed on the catalyst sites. 

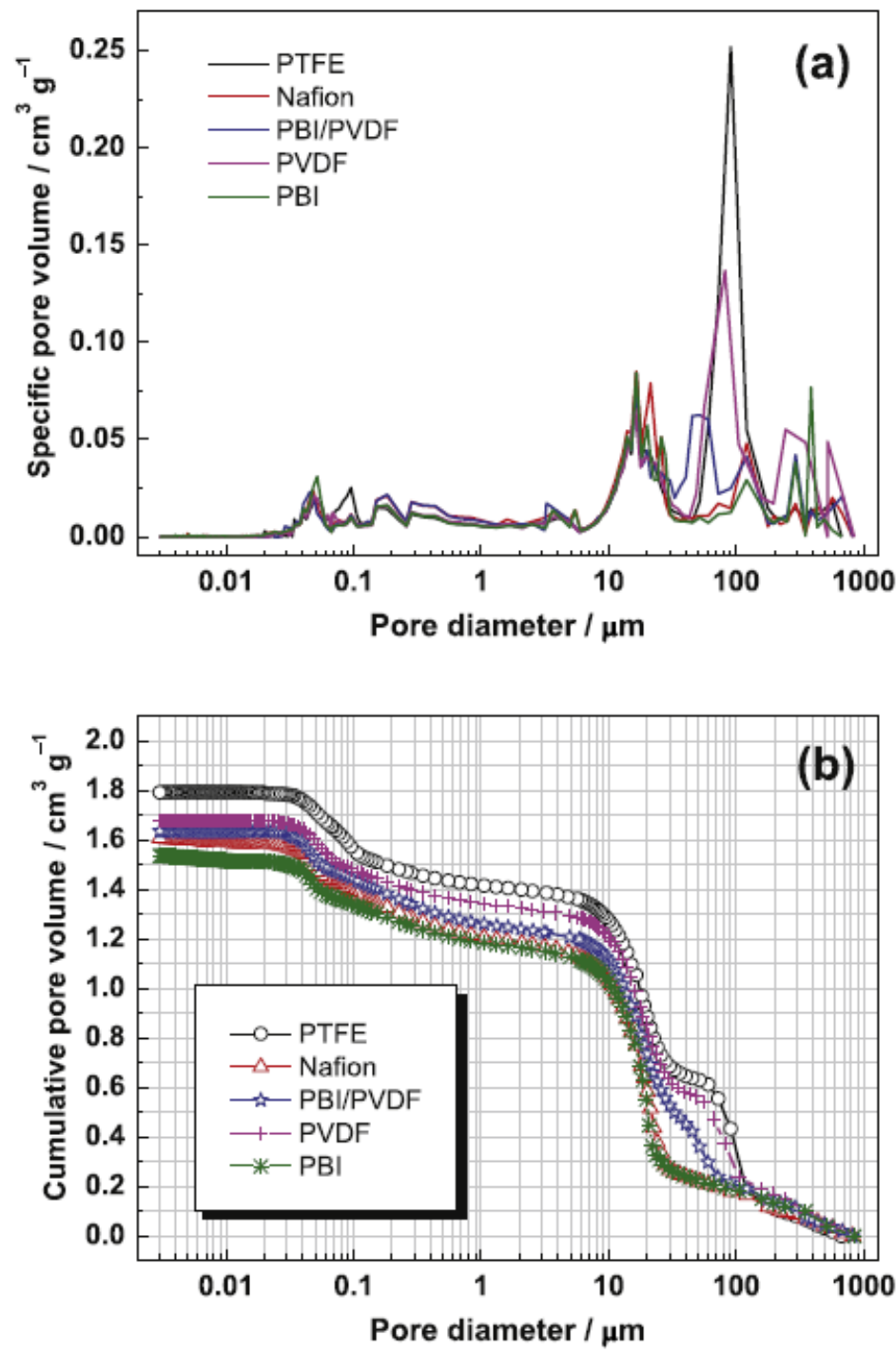

Fig. 2 - (a) Specific and (b) cumulative pore volume distribution of the electrodes with different polymer binders.
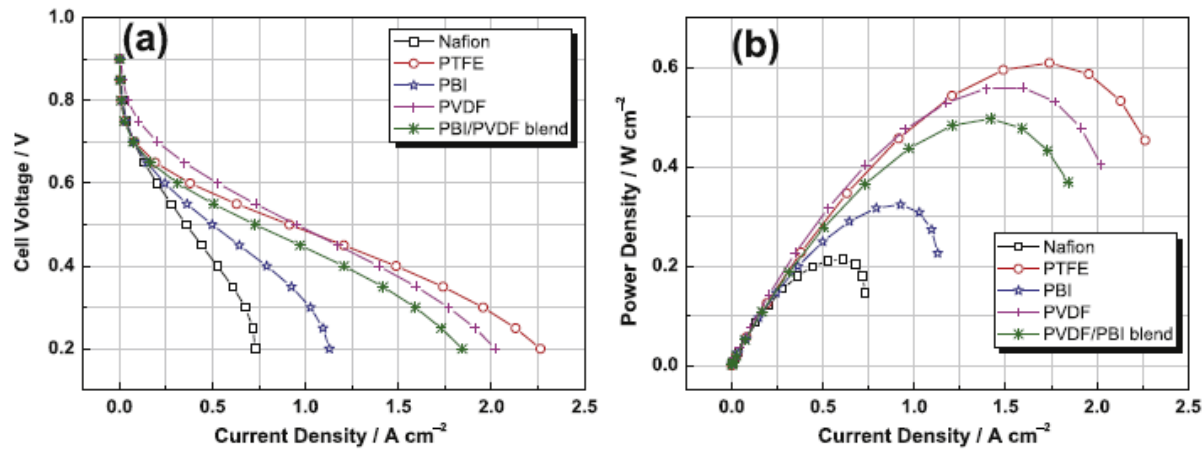

Fig. 3 - Polarization curves (a) and power density curves (b) of PA-doped ABPBI fuel cell using GDEs prepared with different polymer binders, operated at atmosphere pressure and $160^{\circ} \mathrm{C}$. 


\subsection{Electrochemical characteristics}

Fig. 4(a) shows the in situ impedance curves of the single cell with different GDEs at a cell voltage of $0.6 \mathrm{~V}$. Only one semi-circular loop can be observed in the Nyquist plot, as the electrode process is dominated only by the interfacial kinetics of the ORR process. The high-frequency intercept on the real axis represents the total ohmic resistance of the single cell. The diameter of the arc is a measure of the charge transfer resistance of the ORR [33]. A Randels model will be sufficient to simulate this behavior [33], as shown in Fig. 4(b).

Through simulation with Autolab software, the cell resistances (RU) and charge transfer resistances ( $R_{c t}$ ) of the MEAs can be calculated, as listed in Table 2. It can be seen that there is no significant difference in cell ohmic resistance for the MEAs with PTFE, PVDF and PBI/PVDF blend binders, because these MEAs were fabricated by same technique and with the same membrane and same catalyst powder. Also, the cell components were kept under the same conditions for all tests, so the ohmic resistances of each component (i.e. the membrane, GDEs and bipolar plates) and the interfacial contact resistances between them are almost same for these MEAs. The cell resistances showed in the impedance spectrums are consistent with the decreasing slopes in the linear region presented in Fig. 4(a). For the MEAs with PBI and Nafion binders, the ohmic resistances are higher than that of the other three, which may arise from the isolated catalyst agglomerates in the CLs because of the cover effect of the PBI and Nafion binders, as mentioned above. From Table 2, it is clear that the charge transfer resistance of the MEA with PVDF GDEs is much smaller than that of the other GDEs, which suggests that PVDF GDE has more efficient electrochemical active layer. It can be attributed to the properties of PVDF binder, as this is the main difference between these GDEs. These results are certainly consistent with their performances showed in Fig. 4: the lower the charge transfer resistance, the higher the single cell performance.

Fig. 5 shows the cyclic voltammograms of the MEAs with various GDEs. The corresponding EASAs were calculated from $\mathrm{H}_{2}$ desorption peak of the voltammogram [34] and the results are also summarized in Table 2. 

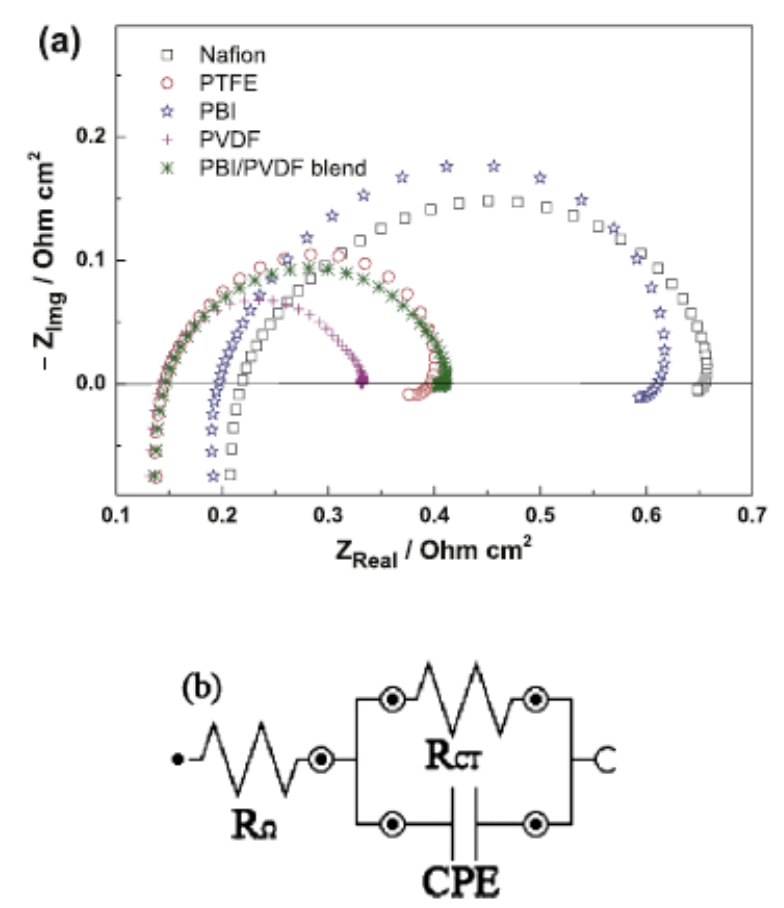

Fig. 4 - (a) In situ impedance curves of the single cell with different GDEs at a cell voltage of $0.6 \mathrm{~V}$. (b) Equivalent circuit used to fit the experimental data shown in (a).

Table 2 - Electrochemical characteristics of the single cell
with electrodes prepared with different polymer binders.
\begin{tabular}{lccc} 
GDE type & $\mathrm{R}_{\Omega}\left(\Omega \mathrm{cm}^{2}\right)$ & $\mathrm{R}_{\mathrm{ct}}\left(\Omega \mathrm{cm}^{2}\right)$ & EASA $\left(\mathrm{m}^{2} \mathrm{~g}^{-1}\right)$ \\
\hline Nafion GDE & 0.221 & 0.446 & 19.6 \\
PTFE GDE & 0.146 & 0.251 & 36.8 \\
PBI GDE & 0.197 & 0.426 & 17.8 \\
PVDF GDE & 0.143 & 0.173 & 38.4 \\
PBI-PVDF GDE & 0.145 & 0.283 & 32.7 \\
\hline
\end{tabular}

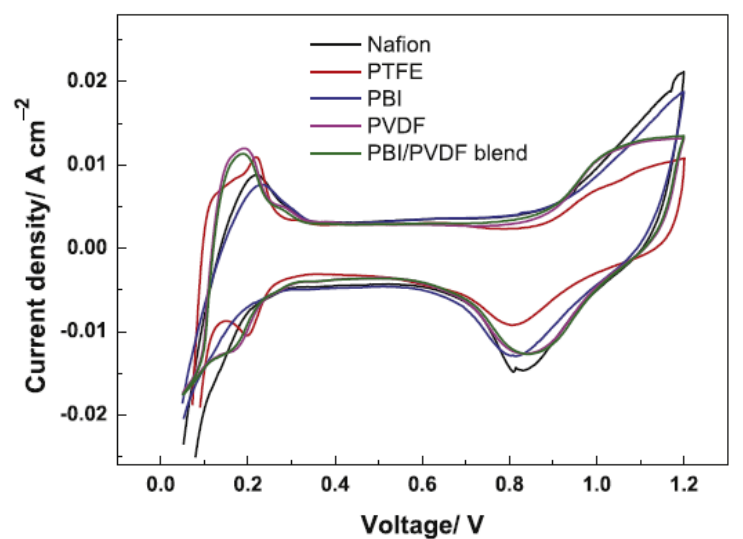

Fig. 5 - Cyclic voltammograms of the MEAs with different GDEs.

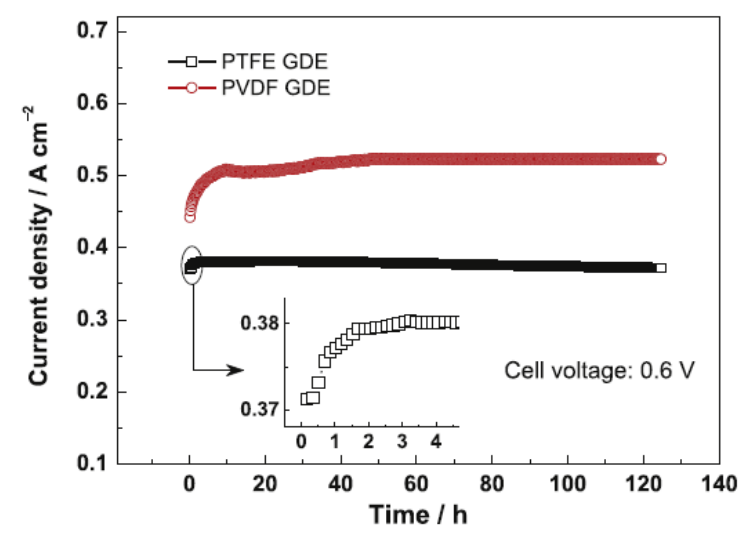

Fig. 6 - The stability tests of single cells with PTFE GDEs and PVDF GDEs operated at $160^{\circ} \mathrm{C}$ and ambient pressure.

\section{http://repository.uwc.ac.za}


Generally, the EASA depends on the structure of the CL, as well as the distribution of the electrolyte (i.e. PA, in case of PBI-base HT-PEMFC) in the CL. As it can be seen in Table 2, there is a significant increase in the EASA when PTFE and PVDF are used as binders in the CLs. It is reasonable when considering the superior CL structures of these two GDEs, making more Pt surface available and better PA distribution in the CLs. However, for the CL with Nafion or PBI binder, it would be more possible for the ionomers to surround the catalyst particles, blocking the electron conduction, and therefore decreasing the platinum utilization, since an ionomer is an electronic insulator. It should be mentioned that all CV measurements were conducted at room temperature (w25 $\mathrm{O}$ C) to get a clear $\mathrm{H}_{2}$ desorption peak, which are almost undetectable at high temperature test due to the very fast desorption process. This may explain why the EASA of the Nafion GDE is a little higher than that of the PBI GDE, although the latter has better performance in the fuel cell test (Fig. 4). The contact between the platinum and electrolyte increased because the Nafion binder in CL is proton conductive at room temperature.

\subsection{Stability}

From the above physical characterizations and electrochemical analysis results, it can be concluded that the good performances of GDEs with the PTFE and PVDF binders are primarily attributable to the superior CL structure resulting from the binders used, which makes a more efficient electrochemical active layer, accordingly a minor kinetic over-potential and charge transfer resistance. So PTFE and PVDF are preferred polymer binders for GDE preparation in our study. However, the stability or durability of GDE is also a major concern for the real application and commercialization of HT-PEMFC. The remarkable long term stability of PAdoped PBI MEA has been reported in the literature [35e38]. To verify the stabilities of the MEAs with these two kind of GDEs (PVDF and PTFE GDE), short term durability tests were performed at $160 \mathrm{O} \mathrm{C}$ and $0.6 \mathrm{~V}$, as shown in Fig. 6.

For the MEA with PTFE GDEs, it can be seen that the current density quickly reached a stable value in less than $4 \mathrm{~h}$ (small insert in Fig. 6), which is mainly attributed to the properties of the PTFE binder. In the CL, the PA is less likely to combine with the PTFE binder due to its high hydrophobicity, which makes most PA freely mobile in the whole CL. Normally, the conductivity and the oxygen diffusion in PA are much higher for PA-doped binders [39], so the PTFE GDEs with free mobile PA in CL reduce the time needed for the MEA activation. This is believed to be one of the advantages of the PTFEbased electrodes over the conventional PBI-based electrodes [29], as the

\section{http://repository.uwc.ac.za}


latter normally require days even weeks of activation in order to achieve the best operating conditions [34,40,41]. For the MEA with PVDF GDEs, it took almost $40 \mathrm{~h}$ of activation before reaching its best performance.

After the activations, both the MEAs exhibited good stabilities at the working voltage of $0.6 \mathrm{~V}$ : the current densities remained at w0.52 $\mathrm{A} \mathrm{cm}^{-2}$ (PVDF GDE) and wo.38 $\mathrm{A} \mathrm{cm}^{-2}$ (PTFE GDE), respectively, without obvious drop after $125 \mathrm{~h}$ operation at $160 \mathrm{O}$. The degradation rates calculated by linear fitting of current density data points after the activations are about $6.4 \mathrm{~mA} \mathrm{~cm}^{-2} \mathrm{~h}^{-1}$ (PVDF GDE) and $68.2 \mathrm{~mA} \mathrm{~cm}^{-2} \mathrm{~h}^{-1}$ (PTFE GDE), respectively, which are acceptable for most applications [35,38,42,43].

\section{Conclusions}

Five polymer binders (Nafion, PBI, PTFE, PVDF and PBIePVDF blend) were evaluated to optimizing the GDE performance of PBI-based HT-PEMFC. Conventional Nafion and PBI polymer are found to be less attractive as binders and ionic conductors in the CLs of HT-PEMFC. PTFE and PVDF are preferred polymer binders for high performance GDEs for HT-PEMFC due to the superior CL structure and electrochemical properties of these GDEs. At the working voltage of $0.6 \mathrm{~V}$, the current density of the MEA with PVDF GDEs can be as high as $0.52 \mathrm{~A} \mathrm{~cm}^{-2}$; the maximum power density of $0.61 \mathrm{~W} \mathrm{~cm}^{-2}$ was reached by using PTFE GDEs. At $0.6 \mathrm{~V}$ and $160{ }^{\circ} \mathrm{C}$, a short-term test showed that both the PTFE and PVDF GDEs have good stabilities for fuel cell application.

\section{Acknowledgments}

This work is supported by Hydrogen and Fuel Cell Technologies RDI Programme (HySA), funded by the Department of Science and Technology in South Africa (project KP1-So1). 


\section{References}

[1] Zhang J, Xie Z, Zhang J, Tang Y, Song C, Navessin T, et al. High temperature PEM fuel cells. J Power Sources 2006;160(2):872-91.

[2] Krishnan P, Park J-S, Kim C-S. Performance of a poly(2,5-benzimidazole) membrane based high temperature PEM fuel cell in the presence of carbon monoxide. J Power Sources 2006;159(2):817-23.

[3] Song C, Tang Y, Zhang JL, Zhang J, Wang H, Shen J, et al. PEM fuel cell reaction kinetics in the temperature range of $23 \mathrm{e} 120 \mathrm{O}$ C. Electrochim Acta 2007;52(7):2552-61.

[4] Jensen JO, Li Q, Pan C, Vestbø AP, Mortensen K, Nybo Petersen H, et al. High temperature PEMFC and the possible utilization of the excess heat for fuel processing. Int J Hydrogen Energy 2007;32(10e11):1567-71.

[5] Peighambardoust SJ, Rowshanzamir S, Amjadi M. Review of the proton exchange membranes for fuel cell applications. Int $\mathrm{J}$ Hydrogen Energy 2010;35(17):9349-84.

[6] Hsueh KL, Gonzalez E, Srinivasan S, Chin DT. Effects of phosphoric acid concentration on oxygen reduction kinetics at platinum. J Electrochem Soc 1984;131:823-8.

[7] Mamlouk M, Scott K. The effect of electrode parameters on performance of a phosphoric acid-doped PBI membrane fuel cell. Int J Hydrogen Energy 2010;35(2):784-93.

[8] Wannek C, Lehnert W, Mergel J. Membrane electrode assemblies for high-temperature polymer electrolyte fuel cells based on poly(2,5benzimidazole) membranes with phosphoric acid impregnation via the catalyst layers. J Power Sources 2009;192(2):258-66.

[9] Pan C, Li Q, Jensen JO, He R, Cleemann LN, Nilsson MS, et al. Preparation and operation of gas diffusion electrodes for high-temperature proton exchange membrane fuel cells. J Power Sources 2007;172(1):278-86.

[10] von Kraemer S, Puchner M, Jannasch P, Lundblad A, Lindbergh G. Gas diffusion electrodes and membrane electrode assemblies based on a sulfonated polysulfone for high-temperature PEMFC. J Electrochem Soc 2006;153(11):A2077-84.

[11] Kim H-J, An SJ, Kim J-Y, Moon JK, Cho SY, Eun YC, et al. Polybenzimidazoles for high temperature fuel cell applications. Macromol Rapid Commun 2004;25(15):1410-3.

[12] Lobato J, Cañ izares P, Rodrigo MA, Linares JJ, Pinar FJ. Study of the influence of the amount of $\mathrm{PBIeH}_{3} \mathrm{PO}_{4}$ in the catalytic layer of a high temperature PEMFC. Int J Hydrogen Energy 2010;35(3):1347-55.

[13] Ong A-L, Jung G-B, Wu C-C, Yan W-M. Single-step fabrication of ABPBIbased GDE and study of its MEA characteristics for high-temperature PEM fuel cells. Int J Hydrogen Energy 2010;35(15):7866-73. 
[14] Zhai Y, Zhang H, Xing D, Shao Z-G. The stability of Pt/C catalyst in $\mathrm{H}_{3} \mathrm{PO}_{4}$ /PBI PEMFC during high temperature life test. J Power Sources 2007;164(1):126-33.

[15] Liu G, Zhang H, Hu J, Zhai Y, Xu D, Shao Z-g. Studies of performance degradation of a high temperature PEMFC based on $\mathrm{H}_{3} \mathrm{PO}_{4}$-doped PBI. $\mathrm{J}$ Power Sources 2006;162(1):547-52.

[16] Liu G, Zhang H, Zhai Y, Zhang Y, Xu D, Shao Z-g. Pt4ZrO2/C cathode catalyst for improved durability in high temperature PEMFC based on $\mathrm{H}_{3} \mathrm{PO}_{4}$ doped PBI. Electrochem Commun 2007;9(1):135-41.

[17] Zhai Y, Zhang H, Zhang Y, Xing D. A novel $\mathrm{H}_{3} \mathrm{PO}_{4} /$ NafionePBI composite membrane for enhanced durability of high temperature PEM fuel cells. $J$ Power Sources 2007;169(2):259-64.

[18] Park JO, Kwon K, Cho MD, Hong SG, Kim TY, Yoo DY. Role of binders in high temperature PEMFC electrode. J Electrochem Soc 2011;158(6):B675-81.

[19] Modestov AD, Tarasevich MR, Filimonov VY, Leykin AY. Influence of catalyst layer binder on catalyst utilization and performance of fuel cell with polybenzimidazole- $\mathrm{H}_{3} \mathrm{PO}_{4}$ Membrane. J Electrochem Soc 2009;156(5):B650-6.

[20] Mazú r P, Soukup J, Paidar M, Bouzek K. Gas diffusion electrodes for high temperature PEM-type fuel cells: role of a polymer binder and method of the catalyst layer deposition. J Appl Electrochem 2011;41(9):1013-9.

[21] Su H, Pasupathi S, Bladergroen BJ, Linkov V, Pollet BG. Enhanced performance of polybenzimidazole-based high temperature proton exchange membrane fuel cell with gas diffusion electrodes prepared by automatic catalyst spraying under irradiation technique. J Power Sources 2013;242:5109.

[22] Kim J-H, Kim H-J, Lim T-H, Lee H-I. Dependence of the performance of a high-temperature polymer electrolyte fuel cell on phosphoric acid-doped polybenzimidazole ionomer content in cathode catalyst layer. J Power Sources 2007;170(2):275-80.

[23] Kongstein OE, Berning T, Børresen B, Seland F, Tunold R. Polymer electrolyte fuel cells based on phosphoric acid doped polybenzimidazole (PBI) membranes. Energy 2007;32(4):418-22.

[24] Hwang DS, Park CH, Yi SC, Lee YM. Optimal catalyst layer structure of polymer electrolyte membrane fuel cell. Int $J$ Hydrogen Energy 2011;36(16):9876-85.

[25] Lee H-K, Park J-H, Kim D-Y, Lee T-H. A study on the characteristics of the diffusion layer thickness and porosity of the PEMFC. J Power Sources 2004;131(1-2):200-6.

[26] Kong CS, Kim D-Y, Lee H-K, Shul Y-G, Lee T-H. Influence of pore-size distribution of diffusion layer on mass-transport problems of proton exchange membrane fuel cells. J Power Sources 2002;108(1-2):185-91. 
[27] Zhang J, Tang Y, Song C, Zhang J. Polybenzimidazole-membrane-based PEM fuel cell in the temperature range of 120-200 O C. J Power Sources 2007;172(1):163-71.

[28] Lobato J, Rodrigo MA, Linares JJ, Scott K. Effect of the catalytic ink preparation method on the performance of high temperature polymer electrolyte membrane fuel cells. J Power Sources 2006;157(1):284-92.

[29] Mamlouk M, Scott K. Phosphoric acid-doped electrodes for a PBI polymer membrane fuel cell. Int J Energy Res 2011;35(6):507-19.

[30] Shao Y, Yin G, Wang Z, Gao Y. Proton exchange membrane fuel cell from low temperature to high temperature: material challenges. J Power Sources 2007;167(2):235-42.

[31] Hogarth WHJ, Diniz da Costa JC, Lu GQ. Solid acid membranes for high temperature ( $>140$ o C) proton exchange membrane fuel cells. J Power Sources 2005;142(1e2):223-37.

[32] Matar S, Higier A, Liu H. The effects of excess phosphoric acid in a Polybenzimidazole-based high temperature proton exchange membrane fuel cell. J Power Sources 2010;195(1):181-4.

[33] Yuan XZ, Wang HJ, Sun JC, Zhang JJ. AC impedance technique in PEM fuel cell diagnosis e a review. Int J Hydrogen Energy 2007;32(17):4365-80.

[34] Jung G-B, Tseng C-C, Yeh C-C, Lin C-Y. Membrane electrode assemblies doped with $\mathrm{H}_{3} \mathrm{PO}_{4}$ for high temperature proton exchange membrane fuel cells. Int J Hydrogen Energy 2012;37(18):13645-51.

[35] Schmidt TJ, Baurmeister J. Properties of high-temperature PEFC Celtec ${ }^{\circledR}-\mathrm{P} 1000$ MEAs in start/stop operation mode. J Power Sources 2008;176(2):428-34.

[36] Oono Y, Sounai A, Hori M. Long-term cell degradation mechanism in high-temperature proton exchange membrane fuel cells. J Power Sources 2012;210:366-73.

[37] Oono Y, Fukuda T, Sounai A, Hori M. Influence of operating temperature on cell performance and endurance of high temperature proton exchange membrane fuel cells. J Power Sources 2010;195(4):1007-14.

[38] Yu S, Xiao L, Benicewicz BC. Durability Studies of PBI-based high temperature PEMFCs. Fuel Cells 2008;8(3-4):165-74.

[39] Liu Z, Wainright JS, Litt MH, Savinell RF. Study of the oxygen reduction reaction (ORR) at Pt interfaced with phosphoric acid doped polybenzimidazole at elevated temperature and low relative humidity. Electrochim Acta 2006;51(19):3914-23.

[40] Boaventura M, Mendes A. Activation procedures characterization of MEA based on phosphoric acid doped PBI membranes. Int $J$ Hydrogen Energy 2010;35(20):11649-60.

[41] Seland F, Berning T, Børresen B, Tunold R. Improving the performance of high-temperature PEM fuel cells based on PBI electrolyte. J Power Sources 2006;160(1):27-36. 
[42] Wannek C, Kohnen B, Oetjen HF, Lippert H, Mergel J. Durability of ABPBIbased MEAs for high temperature PEMFCs at different operating conditions. Fuel Cells 2008;8(2):87-95.

[43] Modestov AD, Tarasevich MR, Filimonov VY, Zagudaeva NM. Degradation of high temperature MEA with $\mathrm{PBI}_{3} \mathrm{H}_{3} \mathrm{PO}_{4}$ membrane in a life test. Electrochim Acta 2009;54(27):7121-7. 